\title{
Quantity restrictions and endogenous quality choice
}

\author{
Iñigo Herguera ${ }^{\mathrm{a}}$, Praveen Kujal ${ }^{\mathrm{b}, *}$, Emmanuel Petrakis ${ }^{\mathrm{c}}$ \\ ${ }^{a}$ Universidad Complutense de Madrid, Madrid, Spain \\ ${ }^{\mathrm{b}}$ Departamento de Economía, Universidad Carlos III de Madrid, Calle Madrid, 126, 28903 Getafe, \\ Madrid, Spain \\ ${ }^{\mathrm{c}}$ University of Crete, Crete, Greece
}

\begin{abstract}
In a vertical product differentiation model under Cournot competition both foreign and domestic firms respond by lowering their investment in long-run quality for a quantity restriction at, and in the neighborhood of, the free trade import level. Average quality increases only when the low-quality foreign firm faces a substantially restrictive quota/ voluntary export restraint. The change in quality depends on whether the foreign firm is of high or low quality and upon the restrictiveness of the quota. The imposition of quantity restrictions has important strategic effects on the long-run choice of quality.
\end{abstract}

Keywords: Vertically differentiation; Quotas; VERs; Quality downgrading

JEL classification: $\mathrm{F} 12$

\section{Introduction}

The issue of quality choice under the imposition of quantity restrictions (QR) has received considerable attention in international trade policy. Theoretical models of quality choice can be classified into two categories, sequential and

\footnotetext{
${ }^{*}$ Corresponding author Tel : +34-91-624-9651; fax: +34-91-624-9875

E-mail address: kujal@eco uc3m es (P Kujal)
} 
simultaneous. In sequential choice models firms invest in quality before they compete in the market in prices or quantities. Quality costs are thus sunk in the market competition stage. In this sense investment in quality is considered a long-run variable in these models. These models have received much attention in papers by Gabszewicz and Thisse, 1980, 1986; Shaked and Sutton, 1982, 1983, 1984; Sutton (1992); Motta (1993) among others. In contrast, in simultaneous choice models quality choice is a short-run variable (as referred to by Feenstra, 1988 ) in the sense that quality costs are borne during the market competition stage. Thus, the two approaches suggest quite distinct testable implications for empirical studies. ${ }^{1}$

Results from empirical studies tend towards significant quality improvements in the year immediately following the imposition of the quantity restriction. Feenstra (1988) finds evidence of quality upgrading for cars with ambiguous change in quality for trucks. Boorstein and Feenstra (1991) show quality upgrading for the steel industry in the year immediately after the imposition of the quota, while Aw and Roberts (1986) find evidence of quality upgrading for shoe imports to the US. None of these papers study the effects of imposing a quantity restriction on long-run investment in quality by a firm.

Most of the theoretical models of quality choice in the international trade literature fall into the category of simultaneous choice models. ${ }^{2,3}$ These models predict quality upgrading under perfect competition. For the case of a foreign monopolist selling in the home market Krishna (1987) finds an increase in the quality of the imports due to the imposition of an import quota whenever consumers with a higher valuation of the good are willing to pay more for the higher quality, i.e., $P_{x q}<0(P(x, q)$ is the inverse demand curve, $x$ is output and $q$ is quality). A restrictive quota removes marginal consumers from the market and the monopolist, who only cares about the marginal consumer, has an incentive to upgrade its quality. Otherwise, quality is downgraded. Das and Donnenfeld (1989) study an oligopoly where firms decide simultaneously on output and quality. In their model, while imposing a quota at the free trade level does not change the quality of the domestic or the foreign firm, QRś strictly below (the free trade level of imports) always increase the quality of the imported good. The domestic firm also upgrades its quality, but only if the foreign firm is the high-quality producer;

\footnotetext{
${ }^{1}$ We are not referring to the case where a firm produces different models and is able to substitute inputs across models due to change in market conditions (this possibility is referred to by Feenstra, 1988). None of the theoretical models mentioned above captures such a scenario.

${ }^{2}$ See Falvey (1979); Santoni and Van Cott (1980); Das and Donnenfeld (1987), (1989) (among others). For a summary of results on perfect competition and monopoly, and for a very good selective survey on export restraints with imperfect competition see Krishna (1990).

${ }^{3}$ For a monopolist the simultaneous or sequential choice models are equivalent. We would like to thank Simon Anderson for pointing this out to us.
} 
otherwise it downgrades. The intuition is similar to the monopoly case. Restricted by the quota, the foreign firm extracts a higher surplus from the high-valuation consumers by upgrading its quality. Ries (1993) extends this result to the case of a multiproduct oligopoly. In Das and Donnenfeld (1987), (1989) and Ries, however, quality choice is a short-run variable. Simultaneity in the choice of quality and output removes the ability of a firm to manipulate its rival's quantity by committing to a level of quality. ${ }^{4}$

In this paper we study the effect of QR's on endogenous quality choice when quality is a long-run strategic variable. A vertical product differentiation model, with a foreign and a domestic firm, is analyzed for the case of imposition of QR's such as Voluntary Export Restraints (VER), or import quotas. The government first commits to an import quota, or equivalently the foreign country commits to a VER. Then firms simultaneously choose their qualities bearing quality costs at this stage. In the following stage they compete in quantities in the domestic market.

We show that both the foreign and the domestic firms downgrade their qualities for a QR imposed at the free trade level of imports. This contrasts with Das and Donnenfeld (1989), (1989), who show that the quota only has an impact on quality if it is strictly less than the free trade level of imports. Further, downgrading is also observed for quotas greater than or less than the free trade level of imports. This is important because even an ex ante non-restrictive level of QR has strategic effects. A high- or low-quality foreign firm always downgrades its quality in response to any import restriction. When the domestic firm is low quality it downgrades (its quality) for restrictions close enough to the free trade level; however, it upgrades its quality only for a sufficiently binding QR. Further, if the domestic firm is of high quality then it always downgrades for any level of import restriction.

If quality is chosen prior to the quantity competition stage firms have an incentive to lower qualities in the presence of QR's. A direct consequence of this is that we get higher prices, lower qualities, higher profits, and lower domestic welfare for a quantity restriction imposed not just at free trade, but also above the free trade level of imports.

The paper is structured as follows. The basic model is presented in Section 2. In Section 3 we look at the effect on qualities, firm profits and domestic welfare of ex ante non-restrictive Quantity Restraints. Section 4 analyzes the effects of ex ante binding quotas/VERs. Section 5 shows that quality downgrading for a quota at the

\footnotetext{
${ }^{4}$ If we allow for simultaneous choice of output and quality our results are 'similar' to Das and Donnenfeld (1987), (1989) insofar as we observe no change in quality when the quota is imposed at the free trade level. However, and contrary to Das and Donnenfeld, we get downgrading in quality for the imported good only when the quota is strictly less than the free trade level of imports.

${ }^{5}$ Reitzes (1991) uses a similar approach to analyze the effects of quotas on strategic R\&D investment.
} 
free trade level of imports holds in a more general model. Finally, Section 6 concludes.

\section{The basic model}

We consider the simple case of two countries, foreign and domestic. There are two firms, one located in each country producing a vertically differentiated good and selling in the domestic market. High quality is indexed as $s_{1}$ and low quality as $s_{2}$, with $s_{1}>s_{2}$. We concentrate on the effects of quantity restrictions in the domestic market alone. There is a continuum of consumers in the domestic market, each is identified by his taste parameter $\theta$, where $\theta$ is uniformly distributed over the interval $[0, \Theta]$ with density $1 ; \Theta$ then represents the size of the market. A consumer $\theta$ has unit demand for the good and his utility function is:

$$
U=\begin{array}{cc}
\theta s-p & \text { if he buys one unit of the good of quality } s \text { at a price } p . \\
0 & \text { otherwise. }
\end{array}
$$

Total costs are, $C\left(s_{i}, x_{i}\right)=s_{i}^{2} / 2, i=1,2$. The marginal cost of production is independent of the quality level and quality costs are fixed. Without loss of generality we assume that marginal cost, 0 . This specification of costs captures the distinctive characteristics of (pure) vertical differentiation models. Shaked and Sutton (1983) define a pure vertically differentiated industry as one where the costs of quality improvement fall primarily on fixed costs and involve only a modest, or no, increase in unit variable costs. ${ }^{6}$ Quality costs that are borne in the first stage are treated as being sunk in the production stage (see Sutton, 1992).

The sequence of moves is as follows. First, the government credibly commits to a specific quantity restriction. Equivalently, the domestic government imposes an import quota on the foreign firm, or the foreign government chooses a VER on its own firm. After the government's announcement of the QR, the firms simultaneously choose their qualities, bearing quality costs, $s_{i}^{2} / 2, i=1,2$. The game is solved using sub-game perfection.

To derive the demands for the high- and low-quality good, we define the taste parameter of the consumer indifferent between buying the high- or low-quality good as $\theta_{12}=\left(p_{1}-p_{2}\right) /\left(s_{1}-s_{2}\right)$; and that of the consumer indifferent between buying the low-quality good and not buying at all, as $\theta_{02}=\left(p_{2} / s_{2}\right)$. All consumers

\footnotetext{
${ }^{6}$ In this spirit the Das and Donnenfeld (1989) model is not a pure vertical product differentiation model. They assume that $C\left(s_{i}, x_{i}\right)=x_{i} c\left(s_{i}\right)$, with marginal cost $c($.) a convex function of quality. Quality improvement involves no fixed costs and falls exclusively on the unit variable costs. Although the marginal cost of production is constant for a given quality level, it increases with an increasing rate of quality.
} 
for whom $\Theta \geqslant \theta \geqslant \theta_{12}$ purchase the good with quality $s_{1}$; all consumers for whom $\theta_{12}>\theta \geqslant \theta_{02}$ will purchase quality $s_{2}$; and those described by $\theta_{02}>\theta$ do not buy at all. Then:

$$
\begin{aligned}
& D_{1}\left(p_{1}, p_{2}\right)=\Theta-\left(p_{1}-p_{2}\right) /\left(s_{1}-s_{2}\right) ; \\
& D_{2}\left(p_{1}, p_{2}\right)=\left[\left(p_{1}-p_{2}\right) /\left(s_{1}-s_{2}\right)\right]-\left(p_{2} / s_{2}\right)
\end{aligned}
$$

and the inverse demands are:

$$
p_{1}\left(x_{1}, x_{2}\right)=\Theta s_{1}-s_{1} x_{1}-s_{2} x_{2} ; p_{2}\left(x_{1}, x_{2}\right)=\left[\Theta-x_{1}-x_{2}\right] s_{2} .
$$

Note that the cross derivative of the inverse demand with respect to own quality and own quantity is negative. (This is the condition under which Krishna, 1987 gets quality upgrading for the case of a foreign monopoly.)

To analyze the effects of quantity restrictions we first study quality choice under free trade. Following Motta (1993), for any given pair of qualities $\left(s_{1}, s_{2}\right)$ firm $i$ chooses its quantity to maximize its (gross) profits, $p_{i}\left(x_{i}, x_{j}\right) x_{i}$, given the quantity of its rival $x_{j}$. The reaction functions are:

$$
x_{1}=0.5\left[\Theta-\left(s_{2} x_{2} / s_{1}\right)\right] ; \quad x_{2}=0.5\left(\Theta-x_{1}\right) .
$$

Solving we get the equilibrium quantities,

$$
x_{1}^{*}\left(s_{1}, s_{2}\right)=\Theta\left(2 s_{1}-s_{2}\right) /\left(4 s_{1}-s_{2}\right) ; \quad x_{2}^{*}\left(s_{1}, s_{2}\right)=\Theta s_{1} /\left(4 s_{1}-s_{2}\right)
$$

and the equilibrium net profits are, $\pi_{i}^{*}\left(s_{1}, s_{2}\right)=s_{i} x_{i}^{*^{2}}-\left(s_{i}^{2} / 2\right), i=1,2$. Since $\mathrm{d} x_{i}^{*} / \mathrm{d} s_{j}<0$, firm $j$ has a strategic incentive to increase its quality in the first stage in order to steal business from its rival in the second stage. Due to this business-stealing effect, both firms choose higher qualities than if quality and quantity were chosen simultaneously. In other words, whenever quality is a long-run strategic variable whose costs are sunk, a firm has incentives to commit to a higher quality in order to increase its market share and profits in the market competition stage. This strategic incentive is absent whenever quality is a shortrun variable, and thus free trade equilibrium qualities are lower under the short-run scenario.

In the first stage, taking the quality of its rival $s_{j}$ as given firm $i$ chooses its quality $s_{i}$ to maximize $\pi_{i}^{*}\left(s_{1}, s_{2}\right)$. After some manipulations ${ }^{7}$ we get the free-trade equilibrium qualities, quantities, profits and total domestic welfare from the first-order conditions:

\begin{tabular}{lll}
\hline$s_{1}^{*}=0.252 \Theta^{2}$ & $s_{2}^{*}=0.090 \Theta^{2}$ & $s_{\mathrm{AV}}=0.191 \Theta^{2}$ \\
$x_{1}^{*}=0.451 \Theta$ & $x_{2}^{*}=0.275 \Theta$ & $\lambda^{*}=\left(s_{1}^{*} / s_{2}^{*}\right)=2.792$ \\
$\pi_{1}^{*}=0.019 \Theta^{4}$ & $\pi_{2}^{*}=0.003 \Theta^{4}$ & $T W_{\mathrm{fh}}=0.043 \Theta^{4}$ \\
& & $T W_{\mathrm{fl}}=0.060 \Theta^{4}$ \\
\hline
\end{tabular}

\footnotetext{
${ }^{7}$ For further details see Motta (1993).
} 
Where, $s_{\mathrm{AV}}=\left(x_{1}^{*} s_{1}^{*}+x_{2}^{*} s_{2}^{*}\right) /\left(x_{1}^{*}+x_{2}^{*}\right)$, is the average quality in the market, and $T W_{\mathrm{fl}}\left(T W_{\mathrm{fh}}\right)$ is the total domestic welfare ${ }^{8}$ when the domestic firm produces the low- (high-) quality good.

\section{The effect of ex ante non-restrictive quantity restraints}

We first analyze the effect on the quality configuration of a quota/VER imposed at, or even slightly above, the free trade level of imports. In Das and Donnenfeld (1989) a quantity restraint at the free trade level of imports has no effect on the quality configuration. As firms choose their qualities and quantities simultaneously, a quota imposed at (or, above) the free trade level of imports is not ex post binding. In this case the domestic and the foreign firm select the same qualities as under free trade. Yet, as we will show below, if firms first choose their qualities and then compete in quantities, ex ante non-restrictive quotas do have an effect on the quality configuration. ${ }^{9}$ In fact, both the domestic and the foreign firm downgrade their qualities in the presence of the quota, regardless of whether the foreign firm produces the high- or the low-quality good.

The intuition is rather simple. Let the quota be imposed at the free trade level of imports. As the foreign firm's sales are already restricted by the quota, the domestic firm's incentive to strategically increase its quality in order to reduce its rival's sales is not present anymore. The domestic firm then selects a lower quality than under free trade and thus saves on quality costs. As a result, if the foreign firm is of high (low) quality, the quality gap increases (decreases). Therefore, in order to relax market competition a low-quality foreign firm will also downgrade its quality, maintaining its sales and saving on quality costs. On the other hand, a high-quality foreign firm also downgrades and saves on quality costs while maintaining its sales. Larger quality differentiation thus results in softer market competition. As the quantitative restraint removes some of the strategic effects, it relaxes overall competition and leads to higher prices and profits for the firms. As in Krishna (1989), ex ante nonrestrictive quotas/VERs act as collusion facilitating devices.

Let a quota/VER imposed on the foreign firm be equal, or slightly higher, than the free trade level of imports. ${ }^{10}$ The following proposition summarizes the results:

\footnotetext{
${ }^{8}$ Total domestic welfare is defined here as the (unweighted) sum of consumer surplus and domestic firm's profits.

${ }^{9}$ A qualitatively similar result has been obtained in other contexts. In Krishna (1987) an ex-ante nonrestrictive quota has an affect on the prices chosen by the domestic and the foreign firm. In Reitzes (1991), a nonrestrictive quota alters the decisions on R\&D expenditures of the firms.

${ }^{10}$ See Herguera et al. (1997) for the exact interval of quotas.
} 
Proposition 1. Regardless of whether the foreign firm is of high-or low-quality both the domestic and the foreign firm downgrade their qualities if the quantity restraint is imposed at (or slightly above) the free-trade level of imports. Average quality is lower than under free trade. Firm profits are higher, while total domestic welfare is always lower than under free trade.

Proof: See Appendix A.

If the foreign firm is the high-quality producer then, for a $\mathrm{QR}$ at the free trade level of imports, the equilibrium qualities are $\left(s_{1 \mathrm{H}}^{*}, s_{2 \mathrm{H}}^{*}\right)=\left(0.248 \Theta^{2}, 0.075 \Theta^{2}\right)$. Further, the equilibrium qualities if the foreign firm produces the low-quality good, $\left(s_{1 \mathrm{~L}}^{*}, s_{2 \mathrm{~L}}^{*}\right)=\left(0.248 \Theta^{2}, 0.089 \Theta^{2}\right)$, are lower than the free-trade equilibrium qualities $\left(s_{1}^{*}, s_{2}^{*}\right)$. Note that given the qualities chosen in the first stage, the foreign firm is restricted by the quota in the quantity competition stage; that is, the foreign firm would have increased its quantity, if the QR were not present. ${ }^{11}$ Thus, an ex ante non-restrictive quota becomes ex post restrictive for the foreign firm.

Fig. 1 provides further intuition for our quality downgrading result. Suppose that the foreign firm is high quality and the quota is imposed at the free trade level of imports $\left(Q_{\mathrm{H}}=x_{1}^{*}\right)$. As the reaction function of the domestic firm, $R_{2}\left(x_{1}\right)$, is independent of qualities, the effect on quality choice of a $Q R$ is explained by looking solely at its effect on the reaction function of the foreign firm. The latter now becomes kinked at the level of the quota $\left(Q_{\mathrm{H}} Q_{\mathrm{H}}\right)$. The domestic firm can then decrease its quality [shifting $R_{1}\left(x_{2}\right)$ outwards to $R_{1}^{\prime}\left(x_{2}\right)$ ] and save on quality costs, while maintaining its sales. As quality costs are quadratic, while revenues are linear in quality, domestic firm's profits increase. Meanwhile, the foreign firm also lowers its quality (moving $R_{1}^{\prime}\left(x_{2}\right)$ inwards), maintaining its sales, and thus increasing its profits.

Similarly, when the foreign firm is the low-quality producer (firm 2) the imposition of a quota at the free trade level makes its reaction function kinked at $Q_{\mathrm{L}}=x_{2}^{*}$ (Fig. 1). For the same decrease in its quality [that shifts $R_{1}\left(x_{2}\right)$ to $R_{1}^{\prime \prime}\left(x_{2}\right)$ ] the domestic firm now loses a smaller amount of sales $\left(Q_{\mathrm{H}} B\right)$ than it would have under free trade $\left(Q_{\mathrm{H}} C\right)$. Hence, it has an incentive to lower its quality and save on quality costs. Meanwhile, the foreign firm also saves on quality costs by lowering its quality $\left(R_{1}^{\prime}\left(x_{2}\right)\right.$ shifts outwards) and maintaining its sales. ${ }^{12}$

As a consequence of quality downgrading, average quality in the market is lower in the presence of an ex ante non-restrictive QR than under free trade. As the quota becomes less restrictive average quality increases. However, for the

\footnotetext{
${ }^{11}$ This can be seen by substituting the equilibrium qualities into Eq. (4). The optimal output for the foreign firm is then higher than the $\mathrm{QR}$.

${ }^{12}$ Similar arguments apply for QR's (slightly) above the free trade level. Even for quotas above the free trade level equilibrium qualities are lower than under free trade.
} 


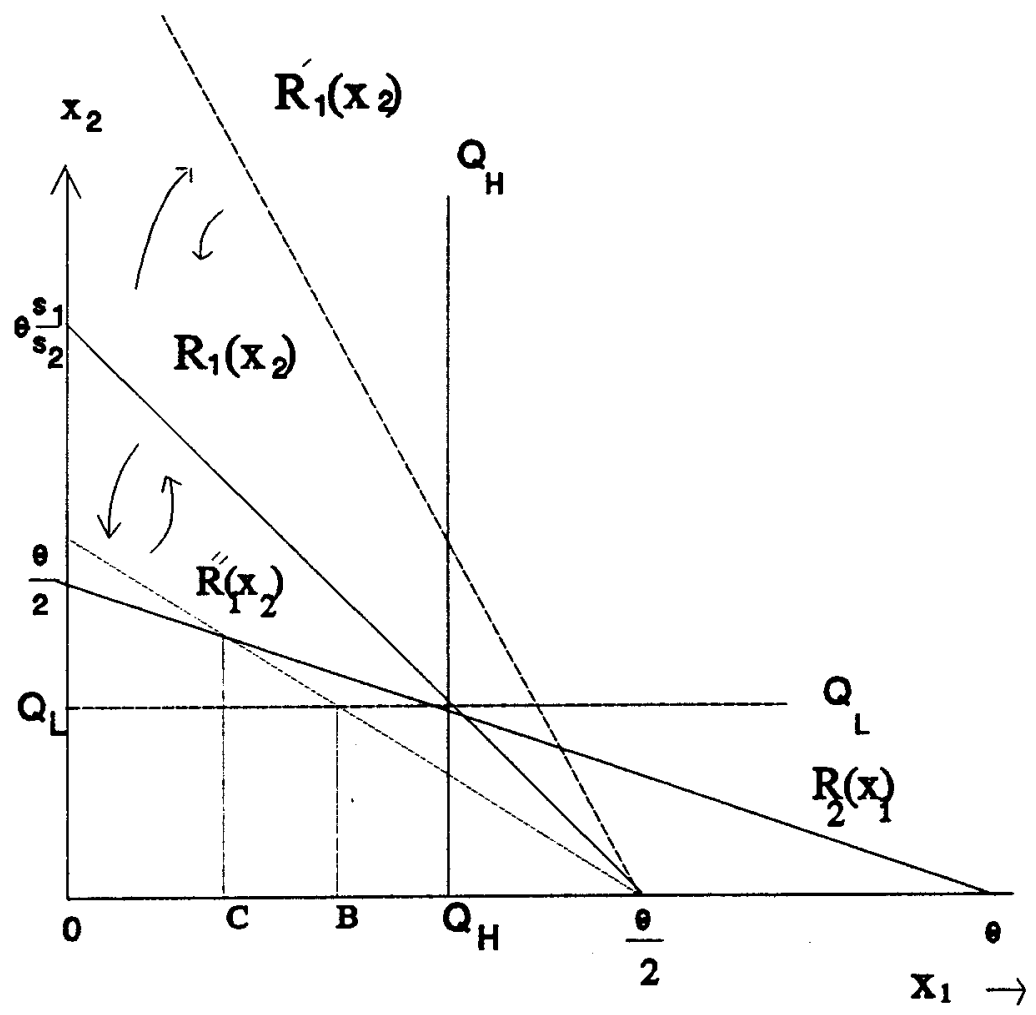

Fig. 1. Best response functions under a Quota on a high- $\left(Q_{H}\right)$ and low-quality $\left(Q_{L}\right)$ firm.

maximum restrictive $\mathrm{QR}$ average quality is $0.184 \Theta^{2}\left(0.188 \Theta^{2}\right)$ when the foreign firm is high (low) quality, which is lower than under free trade. Further, both firms earn higher profits than under free trade. ${ }^{13}$

As the quota restricts the foreign firm's sales ex post, the domestic firm acting as a monopolist on the residual demand chooses its (monopoly) profit maximizing quality. Since the domestic firm's strategic incentive to increase its quality in order to reduce its rival's output is now absent, competition in the quality stage becomes softer. Thus, the foreign firm attains a higher level of profits by lowering its quality. In this sense, QR's facilitate collusion between the foreign and the

\footnotetext{
${ }^{13}$ Profits and Total welfare under quantity restrictions at the free trade level are; $\left(\pi_{1 \mathrm{H}}^{*}, \pi_{2 \mathrm{H}}^{*}\right)=$ $\left(0.021313 \Theta^{4}, 0.002843 \Theta^{4}\right),\left(\pi_{1 \mathrm{~L}}^{*}, \pi_{2 \mathrm{~L}}^{*}\right)=\left(0.01963 \Theta^{4}, 0.0027545 \Theta^{4}\right), T W_{\mathrm{H}}=0.406755 \Theta^{4}$ and $T W_{\mathrm{L}}=$ $0.0591364 \Theta^{4}$.
} 
domestic firm. The facilitating collusion practices result is also observed in our sequential quality-output choice model. ${ }^{14}$

Finally, total domestic welfare under an ex-ante non-restrictive QR is always lower than under free trade. This is true regardless of the quality produced by the foreign firm. A domestic government has no incentive to impose an ex-ante non-restrictive quota on the foreign firm as the decrease in the consumer surplus outweighs the increase in the home firm's profits. However, as we will see in the next section, the domestic government may sometimes opt for an ex-ante restrictive quota. In fact if the foreign firm is low quality the domestic government prefers to totally ban imports. Otherwise, home governments' welfare is maximized under free trade. In contrast, the foreign government prefers to impose a VER on its own firm, since the foreign firm's profits are now higher than under free trade. In fact, as foreign firm's profits increase with the quota, the optimal VER is the maximum QR that becomes ex post restrictive on the foreign firm.

\section{Ex ante restrictive quotas/VERs}

Suppose that a quota strictly less than the free trade level of imports is imposed on the foreign firm. Das and Donnenfeld (1989) show that the foreign firm always upgrades its quality after the imposition of an ex ante restrictive QR. The domestic firm also upgrades its quality but only if it produces the low-quality good; otherwise, it responds to the quota by downgrading its quality. This result is due to the specification of their model. It can be checked that in our (pure) vertical differentiation specification under simultaneous choice of qualities and quantities, the foreign firm (regardless of its quality) responds to a QR by lowering its quality, ${ }^{15}$ on the contrary, the domestic firm upgrades its quality. ${ }^{16}$ Yet, a quota arbitrarily close to the free trade level results in an infinitesimal decrease of the quality of imports when the choice of qualities and quantities is simultaneous, while in a substantial (higher order) decrease if this choice is sequential. Furthermore, we show in the next section that the quality downgrading result even holds under the Das and Donnenfeld (1987), (1989) specification whenever quality is a long-run variable.

\footnotetext{
${ }^{14}$ Note, when firms compete a la Cournot, the imposition of a quota at the free trade level has no influence on the profits of the firms in a simultaneous quality-output choice model. In our case, the imposition of the quantity restriction at the free trade level affects firm profits because market competition is relaxed as firms commit to specific levels of quality.

${ }^{15}$ We would like to thank an anonymous referee for pointing this out to us.

${ }^{16}$ In fact, if the selection of qualities and quantities is simultaneous, then the free trade equilibrium qualities are $s_{1}^{\mathrm{DD}}=0.248 \Theta^{2}$ and $s_{2}^{\mathrm{DD}}=0.073 \Theta^{2}$. It can be also checked that $\mathrm{d} s_{1 \mathrm{H}}^{\mathrm{DD}} / \mathrm{d} Q_{\mathrm{H}}>0, \mathrm{~d} s_{2 \mathrm{H}}^{\mathrm{DD}} / \mathrm{d} Q_{\mathrm{H}}<$ 0 , and $\mathrm{d} s_{1 \mathrm{~L}}^{\mathrm{DD}} / \mathrm{d} Q_{\mathrm{L}}<0, \mathrm{~d} s_{2 \mathrm{~L}}^{\mathrm{DD}} / \mathrm{d} Q_{\mathrm{L}}>0$.
} 
Let the quota be such that no firm has incentive to leapfrog its rival; that is, let $Q_{\mathrm{H}} \in[0.252 \Theta, 0.451 \Theta]^{17}$ and $Q_{\mathrm{L}} \in[0,0.275 \Theta] .{ }^{18}$ As the quota becomes more restrictive, the quality choice of the foreign firm decreases (independent of whether it is high or low quality) while that of the domestic firm increases. For a sufficiently restrictive quota the home firm's quality is higher than under free trade, but only if the foreign firm is of high quality (e.g. $s_{2 \mathrm{H}}^{*}=0.140 \Theta^{2}$ for the lowest possible $Q_{\mathrm{H}}$ ). Average quality, however, decreases as the QR becomes more restrictive and is always lower than under free trade. The increase in sales and quality of the home product does not compensate for the restriction on the imports of the high-quality good whose quality deteriorates. However, if the foreign firm is of low quality, average quality increases. This occurs due to a slight increase in the domestic firm's quality ${ }^{19}$ as the quota becomes restrictive, increase in domestic output and restricted sales of the low-quality good. Proposition 2(a) summarizes the results.

Proposition 2(a). Import quality deteriorates as the $Q R$ becomes more restrictive. In contrast, there is an improvement in quality of the domestic good. As the quota becomes more restrictive, total output decreases, while average quality increases (decreases) if the foreign firm is of low (high) quality. Average quality is lower than under free trade, except if the quota is sufficiently restrictive and the foreign firm is of low quality.

Proof. See Appendix A.

As a quota/VER becomes restrictive the profits of the foreign firm decrease, while those of the home firm increase. The foreign government thus never opts for a VER strictly less than the free trade level of imports.

If the foreign firm is of high quality, the domestic government prefers free trade over any level of QR. The increase in the home firm's profits is not enough to compensate for the consumer welfare loss (both average quality and total output decrease). Total welfare is higher under free trade than under any level of quota. If the foreign firm is of low-quality consumer welfare loss is of a lower magnitude (as average quality increases) and is compensated by the increase in home firm's

\footnotetext{
${ }^{17}$ We restrict attention to quantity restrictions such that neither of the firms has an incentive to leapfrog its rival. That is, the condition that a high (low) quality firm would not choose to produce the low (high) quality good is always satisfied. This defines the lower limit for $Q_{\mathrm{H}}$. For the proof, that no firm has incentive to leapfrog its rival for $Q_{\mathrm{H}} \geqslant 0.252 \Theta$ see Herguera et al. (1994). In a related paper (Herguera et al., 1996) we analyze the implications on quality choice of very restrictive import quotas/VERs.

${ }^{18}$ It can be checked that no firm has incentive to leapfrog its rival for all $Q_{\mathrm{L}} \leqslant 0.275 \Theta$. For the proof see Herguera et al. (1994).

${ }^{19}$ Note that the domestic firm quality never exceeds the free trade level of quality.
} 
profits. Total domestic welfare achieves its maximum when the foreign firm is completely shut out of the market (for $Q_{\mathrm{L}}=0, T W_{\mathrm{L}}=0.063 \Theta^{4}>T W^{*}=0.060 \Theta^{4}$ ) and is higher than under free trade. Thus, the home country prefers to completely shut out imports of the low-quality good. The above results are summarized in Proposition 2(b).

Proposition 2(b). As the $Q R$ becomes restrictive the profits of the home firm increase, while the profits of the foreign firm decrease. When the foreign firm is of high quality, total domestic welfare is always lower than under free trade. In contrast, if the foreign firm is of low-quality, total domestic welfare increases as the quota becomes more restrictive, and is greater than under free trade for sufficiently restrictive quotas.

Proof. See Appendix A.

\section{A more general model}

In this section we generalize the model presented in Section 2. The generalization refers to the specification of the domestic market and the cost functions. There is a continuum of consumers, each consuming a unit (or none) of the good and having utility:

$$
U=\begin{array}{cc}
\theta u(s)-p & \text { if he buys the good of quality } s \text { at a price } p . \\
0 & \text { otherwise. }
\end{array}
$$

$u(s)$ is a common valuation function of quality and is assumed to be concave, i.e., $u^{\prime}>0$ and $u^{\prime \prime} \leqslant 0$. The taste parameter, $\theta$, is distributed according to some density $f(\theta)$ with cumulative distribution function $F(\theta)$ on $[0,+\infty)$ where $F(0)=0$ and $F(+\infty)=1$. We assume that the hazard rate of $f, f(\theta) /[1-F(\theta)]$, is increasing ${ }^{20}$ in $\theta^{21}$. The total mass of consumers equals $m$. In general, firms employ different technologies. Firm $i$ producing output $y_{i}$ and quality $s_{i}$ has total costs $C_{i}\left(y_{i}, s_{i}\right)$, where $\partial C^{i} / \partial y_{i} \equiv M C^{i}>0, \partial C^{i} / \partial s_{i} \equiv M Q C^{i}>0, \partial M C^{i} / \partial y_{i} \geqslant 0$ and $\partial M Q C^{i} / \partial s_{i}>0$. In the spirit of a pure vertical differentiation model where marginal cost changes only slightly with the quality level we assume that $\partial M C^{i} / \partial s_{i}$ is small enough. The bulk of quality improvement costs thus fall upon the fixed costs of production (see Sutton, 1992 for a nice graphical description). Finally, assume that $C^{1}\left(., s_{1}\right) \leqslant$

\footnotetext{
${ }^{20}$ If the density function is log-concave then the hazard rate is increasing.

${ }^{21}$ This is a commonly made assumption in the literature (see, for example, Tirole (1989), p. 156). It is satisfied by many distributions, like the normal, the exponential, the uniform, the logistic, the Pareto, and any distribution with nondecreasing density.
} 
$C^{2}\left(., s_{2}\right)$ for all $s_{1}=s_{2}$. That is, the firm that produces the high quality is at least as efficient as the firm that produces the low quality.

Define $\theta(x)$ such that $1-F(\theta(x))=x$; then $\mathrm{d} \theta(x) / \mathrm{d} x=-[1 / f(\theta(x))]$. Let $\theta_{12}$ denote the consumer who is indifferent between buying the high-, or the low-, quality good. Further, let $\theta_{02}$ be the consumer who is indifferent between buying the low-quality good or not buying at all. Let $p_{i}$ be the price for quality $s_{i}$. Then, $\theta_{02} u\left(s_{2}\right)=p_{2}$ and $\theta_{12}\left[u\left(s_{1}\right)-u\left(s_{2}\right)\right]=p_{1}-p_{2}$. Further, $\theta_{12}=\theta\left(x_{1}\right)$ and $\theta_{02}=\theta\left(x_{1}+\right.$ $x_{2}$ ) and the inverse demands are:

$$
p_{2}=\theta\left(x_{1}+x_{2}\right) u\left(s_{2}\right) ; p_{1}=\theta\left(x_{1}\right) u\left(s_{1}\right)-\left[\theta\left(x_{1}\right)-\theta\left(x_{1}+x_{2}\right)\right] u\left(s_{2}\right)
$$

where, $x_{i}$ represents firm $i$ 's customers per unit mass of consumers. Then the profits are, $\pi^{i}=p_{i} m x_{i}-C^{i}\left(m x_{i}, s_{i}\right), i=1,2$. Under free trade, the first-order conditions determine the equilibrium quantities for any given vector of qualities $\left(s_{1}, s_{2}\right)$,

$$
\begin{aligned}
\pi_{x 2}^{2}= & {\left[\theta\left(x_{1}+x_{2}\right)+\theta_{x 2}\left(x_{1}+x_{2}\right) x_{2}\right] u\left(s_{2}\right)-M C^{2}\left(m x_{2}, s_{2}\right)=0 } \\
\pi_{x 1}^{1}= & {\left[\theta\left(x_{1}\right)+\theta_{x 1}\left(x_{1}\right) x_{1}\right]\left[u\left(s_{1}\right)-u\left(s_{2}\right)\right] } \\
& +\left[\theta\left(x_{1}+x_{2}\right)+\theta_{x 1}\left(x_{1}+x_{2}\right) x_{1}\right] u\left(s_{2}\right)-M C^{1}\left(m x_{1}, s_{1}\right)=0
\end{aligned}
$$

where, $\pi_{x 2}^{2} \equiv \partial \pi^{2} / \partial x_{2}, \theta_{x 2}\left(x_{1}+x_{2}\right) \equiv \partial \theta\left(x_{1}+x_{2}\right) / \partial x_{2}$ etc. Eq. (8) defines firm 1's best response function, $B R_{1}\left(x_{2}, s_{1}, s_{2}\right)$, while Eq. (7) defines firm 2's, $B R_{2}\left(x_{1}, s_{2}\right)$. Note that, $B R_{2}$ does not depend on $s_{1}$, the quality level of the high-quality firm.

The solution to Eqs. (7) and (8) gives us the equilibrium quantities, i.e. $\left[x_{1}^{*}\left(s_{1}, s_{2}\right), x_{2}^{*}\left(s_{1}, s_{2}\right)\right]$. The following properties for the $B R_{i}$ and $x_{i}^{*}, i=1,2$ are established in Appendix B and summarized in Proposition 3.

Proposition 3. The best response functions are downwards sloping with absolute slope of less than 1. Hence, there is a unique solution to Eqs. (7) and (8). The high-quality firm's best response function is increasing in its own quality and decreasing in the quality of low-quality firm $\left(\partial B R_{1} / \partial s_{1}>0, \partial B R_{1} / \partial s_{2}<0\right)$. The best response function for the low-quality firm is increasing in its own quality and independent of the quality choice of the high-quality firm $\left(\partial B R_{2} / \partial s_{1}=0, \partial B R_{2} /\right.$ $\left.\partial s_{2}>0\right)$. As a result, equilibrium outputs are increasing in own quality and decreasing in the rival's quality $\left(\partial x_{i}^{*} / \partial s_{i}>0\right.$ and $\left.\partial x_{i}^{*} / \partial s_{j}<0, i, j=1,2\right)$.

Next turning to the quality selection stage. The profit function of firm $i$ can be written as $\pi^{i}\left(s_{1}, s_{2}, x_{1}^{*}\left(s_{1}, s_{2}\right), x_{2}^{*}\left(s_{1}, s_{2}\right)\right)$ and the foc's are $(i, j=1,2)$,

$$
\mathrm{d} \pi^{i} / \mathrm{d} s_{i}=\pi_{s i}^{i}+\pi_{x i}^{i} \partial x_{i}^{*} / \partial s_{i}+\pi_{x j}^{i} \partial x_{j}^{*} / \partial s_{i}=\pi_{s i}^{i}+\pi_{x j}^{i} \partial x_{j}^{*} / \partial s_{i}=0
$$

(since by the envelope theorem $\pi_{x i}^{i}=0$ ). The first term in Eq. (9) is the direct effect of an increase in firm $i$ 's quality on its own profits. The last term is the 
strategic effect, i.e., an increase in firm i's quality leads to a reduction in its rival's output $\left(\partial x_{j}^{*} / \partial s_{i}<0\right)$, and thus an increase in firm $i$ 's profits, since:

$$
\pi_{x j}^{i}=\theta_{x j}\left(x_{1}^{*}+x_{2}^{*}\right) u\left(s_{2}\right) m x_{i}^{*}=-u\left(s_{2}\right) m x_{i}^{*} / f\left(\theta\left(x_{1}^{*}+x_{2}^{*}\right)\right)<0
$$

This strategic effect is positive, thus firms overinvest in quality in order to steal business from their rivals. Let $\left(s_{1}^{*}, s_{2}^{*}\right)$ be the free trade equilibrium qualities (the solution to the system of Eq. (9)), and let $x_{i}^{*}=x_{i}^{*}\left(s_{1}^{*}, s_{2}^{*}\right), i=1,2$, be the corresponding equilibrium quantities.

\subsection{The effect of a quota imposed at the free trade level of imports}

\subsubsection{Foreign firm high quality}

Suppose that a quota $Q_{\mathrm{H}}=x_{1}^{*}$ is imposed on the foreign firm. Assume, for the moment, that the quota is binding. Then $x_{1}=Q_{\mathrm{H}}$, and $x_{2}=B R_{2}\left(Q_{\mathrm{H}}, s_{2}\right)$ and the profits can be written as $\pi^{i}\left(s_{1}, s_{2}, Q_{\mathrm{H}}, B R_{2}\left(Q_{\mathrm{H}}, s_{2}\right)\right), i=1,2$. The domestic firm's first-order condition in the quality selection stage is:

$$
\mathrm{d} \pi^{2} / \mathrm{d} s_{2}=\pi_{s 2}^{2}+\pi_{x 2}^{2} \partial B R_{2} / \partial s_{2}=\pi_{s 2}^{2}=0
$$

(as $\pi_{x 2}^{2}=0$ ). Now, $\mathrm{d} \pi^{2} / \mathrm{d} s_{2}$ evaluated at $s_{2}=s_{2}^{*}$ is negative and thus $s_{2 \mathrm{H}}<s_{2}^{*}$. The quota removes the strategic effect and the domestic firm maximizing its profits on the residual demand lowers its quality. As $s_{2 \mathrm{H}}<s_{2}^{*}, B R_{1}$ shifts out, while $B R_{2}$ shifts in (see Proposition 3). This implies that the quota $Q_{\mathrm{H}}=x_{1}^{*}$ is indeed binding on the foreign firm. Finally, the foreign firm's foc is given by:

$$
\mathrm{d} \pi^{1} / \mathrm{d} s_{1}=\pi_{s 1}^{1}+\pi_{x 2}^{1} \partial B R_{2} / \partial s_{1}=\pi_{s 1}^{1}=0
$$

This is true as $B R_{2}$ does not depend on $s_{1}$. Now, $\mathrm{d} \pi^{1} / \mathrm{d} s_{1}$ evaluated at $s_{1}=s_{1}^{*}$ is negative. Once more the quota removes the strategic effect and the foreign firm also downgrades its quality, i.e. $s_{1 \mathrm{H}}<s_{1}^{*}$.

\subsubsection{Domestic firm high quality}

The analysis here is similar, with the exception that the quota only partially removes the strategic effect of the foreign firm. Assuming that the quota $Q_{\mathrm{L}}=x_{2}^{*}$ is binding on the low-quality foreign firm, $x_{2}=Q_{\mathrm{L}}$ and $x_{1}=B R_{1}\left(Q_{\mathrm{L}}, s_{1}, s_{2}\right)$. Then the profits can be written as $\pi^{i}\left(s_{1}, s_{2}, B R_{1}\left(Q_{\mathrm{L}}, s_{1}, s_{2}\right), Q_{\mathrm{L}}\right), i=1,2$. The foc of the high-quality domestic firm in the quality selection stage is $\left(\pi_{x 1}^{1}=0\right)$ :

$$
\mathrm{d} \pi^{1} / \mathrm{d} s_{1}=\pi_{s 1}^{1}+\pi_{x 1}^{1} \partial B R_{1} / \partial s_{1}=\pi_{s 1}^{1}=0
$$

Thus, $\mathrm{d} \pi^{1} / \mathrm{d} s_{1}$ evaluated at $s_{1}=s_{1}^{*}$ is negative and hence $s_{1 \mathrm{~L}}<s_{1}^{*}$. The quota removes the strategic effect and the domestic firm chooses its quality maximizing profits solely on the residual demand. As $s_{1 \mathrm{~L}}<s_{1}^{*}, B R_{1}$ shifts in, while $B R_{2}$ remains unchanged. Hence the quota $Q_{\mathrm{L}}=x_{2}^{*}$ is indeed binding on the foreign firm. Finally, the foreign firm's first-order condition is: 


$$
\mathrm{d} \pi^{2} / \mathrm{d} s_{2}=\pi_{s 2}^{2}+\pi_{x 1}^{2} \partial B R_{1} / \partial s_{2}=0
$$

where, $\partial B R_{1} / \partial s_{2}$ is obtained by differentiating Eq. (8) with respect to $s_{2}$ while holding $x_{2}^{*}$ constant at $Q_{\mathrm{L}}$. That is, $\partial B R_{1} / \partial s_{2}=-\left[\pi_{\mathrm{x} 1 \mathrm{~s} 2}^{1} / \pi_{\mathrm{x} 1 \mathrm{x} 1}^{1}\right]<0$. On the other hand, differentiating Eq. (8) with respect to $s_{2}$ and letting $x_{2}^{*}$ adjust accordingly we obtain (the second term is positive):

$$
\partial x_{1}^{*} / \partial s_{2}=-\left[\pi_{x 1 s 2}^{1} / \pi_{x 1 x 1}^{1}\right]-\left[\pi_{x 1 x 2}^{2} / \pi_{x 1 x 1}^{1}\right] \partial x_{2}^{*} / \partial s_{2}<\partial B R_{1} / \partial s_{2}<0
$$

Thus, as $\pi_{x 1}^{2}<0, \pi_{x 1}^{2} \partial B R_{1} / \partial s_{2}<\pi_{x 1}^{2} \partial x_{1}^{*} / \partial s_{2}$. Comparing Eq. (15) and Eq. (9), we get that $\mathrm{d} \pi^{2} / \mathrm{d} s_{2}$ evaluated at $s_{2}=s_{2}^{*}$ is negative, and thus $s_{2 \mathrm{~L}}<s_{2}^{*}$. The strategic effect is smaller in the presence of the quota and thus the foreign firm downgrades its quality. The above results are summarized in the following proposition.

Proposition 4. For a quota imposed at the free trade level of imports, both the foreign and the domestic firm downgrade their qualities, irrespective of whether they produce high or low quality.

Finally, note that the above reasoning can be extended in the case of a quota imposed slightly above, or below, the free trade level of imports.

\section{Conclusions}

Our paper is different from those of our predecessors in the sense that predictions of our model are towards long-run investment in quality. As quality choice is a long-run strategic variable, a firm pre-commits to a quality level before it competes in the market (incurring a sunk cost of improving its quality at an earlier stage). Our results indicate that the imposition of a quantity restriction at, or in the neighborhood of, the free trade level of imports results in lower long-run investment in quality. Only for the case where a very restrictive $Q R$ is imposed on the low-quality foreign firm is average quality higher than under free trade. Further, we get quality downgrading even under the condition for which the foreign monopolist in Krishna (1987) upgrades its quality, i.e., if $P_{x q}<0(P(x, q)$ is the inverse demand curve, $x$ is output and, $q$ is the quality). Also, in contrast to Das and Donnenfeld (1987), (1989), where for a restriction at the free trade level no changes in quality are observed, we get quality downgrading.

Our results highlight the importance of strategic interaction for the choice of quality and the role of the timing of the decisions. In our sequential framework firms first compete in qualities and then in quantities. For a QR imposed on the foreign firm at, or close to, the free trade level the home firm (acting as a monopolist on the residual demand) is able to decrease its quality and thus save on the sunk costs of quality, while barely losing any sales. Similarly, the foreign firm 
also lowers its quality, maintaining its market share, and increases its profit by (also) saving on the costs of quality.

In a structure similar to ours Lutz (1997) has shown that under price competition a quota always leads to downgrading of the high-quality firm regardless of on whom the quota is imposed while, the low-quality firm always upgrades its quality. Thus, price competition does not lead to a complete reversal of our results.

That quantity restrictions work as facilitating practices (as in Harris, 1985; Krishna, 1989) is further reinforced in our framework. After the imposition of the restriction at (or in the neighborhood of) the free trade level both firms lower qualities, raise prices, and attain higher profits. Our analogue of the result is even more striking because quotas work as a facilitating practice device for the case of competition in quantities. This is contrary to the well known result that QR's have no influence on market outcomes when firms compete in quantities. In fact the foreign firm opts for a maximum ex ante nonrestrictive quota as its profits are the highest. While the domestic firm prefers free trade if imports are of high quality and opts for banning them if they are low quality. There are several interesting lines of research that further need to be investigated. We are already analyzing how governments can strategically use policies to provoke leapfrogging to maximize domestic welfare.

\section{Acknowledgements}

The paper was written when Herguera and Petrakis were at the Universidad Carlos III. Thanks are also due to all the participants at the CEPR ERWIT conference at Rome in September 1994, and the participants at the IX Simposio de Analisis Económico (1994) at the Universidad Autonoma, Barcelona. Two referees and especially the editor provided very helpful comments. Herguera acknowledges support from DGICYT No. PB93-235. Kujal and Petrakis acknowledge support from DGICYT No. PB95-287.

\section{Appendix A}

Proof of Propositions 1 and 2. (i) Foreign firm of high-quality (Case H):Let $Q_{\mathrm{H}} \in[0.252235 \Theta, 0.460496 \Theta]$. Given the quantity restriction $Q_{\mathrm{H}}$, for the foreign firm the reaction function is, $x_{1 \mathrm{H}}=\min \left[Q_{\mathrm{H}}, 0.5\left\{\Theta-\left(s_{2} x_{2} / s_{1}\right)\right\}\right]$. We assume, for the moment, that the restriction is binding and then we define the maximum $Q_{\mathrm{H}}$ for which this is true in equilibrium. Thus, $x_{1 \mathrm{H}}^{*}=Q_{\mathrm{H}}$, and $x_{2 \mathrm{H}}^{*}=0.5\left(\Theta-Q_{\mathrm{H}}\right.$ ) (from Eq. (4)) and from Eq. (3) we get $p_{1 \mathrm{H}}^{*}=0.5\left(2 s_{1}-s_{2}\right)\left(\Theta-Q_{\mathrm{H}}\right), p_{2 \mathrm{H}}^{*}=0.5(\Theta-$ $\left.Q_{\mathrm{H}}\right) s_{2}$; hence, the net profits are: 


$$
\begin{aligned}
& \pi_{1 \mathrm{H}}\left(s_{1}, s_{2}\right)=0.5 Q_{\mathrm{H}}\left(2 s_{1}-s_{2}\right)\left(\Theta-Q_{\mathrm{H}}\right)-\left(s_{1}^{2} / 2\right) ; \\
& \pi_{2 \mathrm{H}}\left(s_{1}, s_{2}\right)=0.25\left(\Theta-Q_{\mathrm{H}}\right)^{2} s_{2}-\left(s_{2}^{2} / 2\right)
\end{aligned}
$$

From the first-order conditions we get,

$$
s_{1 \mathrm{H}}^{*}=Q_{\mathrm{H}}\left(\Theta-Q_{\mathrm{H}}\right) ; s_{2 \mathrm{H}}^{*}=0.25\left(\Theta-Q_{\mathrm{H}}\right)^{2}
$$

Hence, $p_{1 \mathrm{H}}^{*}=\left(9 Q_{\mathrm{H}}-\Theta\right)\left(\Theta-Q_{\mathrm{H}}\right)^{2} / 8$, and $p_{2 \mathrm{H}}^{*}=\left(\Theta-Q_{\mathrm{H}}\right)^{3} / 8$. It can now be checked that $Q_{\mathrm{H}} \leqslant 0.5\left[\Theta-\left(s_{2 \mathrm{H}}^{*} x_{2 \mathrm{H}}^{*} / s_{1 \mathrm{H}}^{*}\right)\right]$ for all $Q_{\mathrm{H}} \in[0.252235 \Theta, 0.460496 \Theta]$. Note that $\mathrm{d} s_{1 \mathrm{H}}^{*} / \mathrm{d} Q_{\mathrm{H}}>0$, and $\mathrm{d} s_{2 \mathrm{H}}^{*} / \mathrm{d} Q_{\mathrm{H}}<0 ; \quad s_{1 \mathrm{H}}^{*}=0.248439 \Theta^{2}$ and $s_{2 \mathrm{H}}^{*}=$ $0.07276 \Theta^{2}$ for $Q_{\mathrm{H}}=0.460496 \Theta ; s_{1 \mathrm{H}}^{*}=0.188613 \Theta^{2}$ and $s_{2 \mathrm{H}}^{*}=0.139788 \Theta^{2}$ for $Q_{\mathrm{H}}=0.252235 \Theta$. Finally $s_{1 \mathrm{H}}^{*}=0.24758 \Theta^{2}, s_{2 \mathrm{H}}^{*}=0.075405 \Theta^{2}$, for $Q_{\mathrm{H}}=0.4508 \Theta$ (a quota at the free trade level of imports). Further, from Eq. (A2) we get the average quality,

$$
s_{\mathrm{AVH}}=0.25\left(\Theta^{2}-2 \Theta Q_{\mathrm{H}}+9 Q_{\mathrm{H}}^{2}\right)\left(\Theta-Q_{\mathrm{H}}\right) /\left(\Theta+Q_{\mathrm{H}}\right)
$$

hence, $\mathrm{d} s_{\mathrm{AVH}} / \mathrm{d} Q_{\mathrm{H}}>0$, and $s_{\mathrm{AVH}}=0.182403 \Theta^{2}$ for $Q_{\mathrm{H}}=0.4508 \Theta$. Now from Eq. (A2) we get the equilibrium profits of the foreign and the domestic firm,

$$
\pi_{1 \mathrm{H}}^{*}=\left(5 Q_{\mathrm{H}}-\Theta\right)\left(\Theta-Q_{\mathrm{H}}\right)^{2} Q_{\mathrm{H}} / 8 ; \pi_{2 \mathrm{H}}^{*}=\left(\Theta-Q_{\mathrm{H}}\right)^{4} / 32
$$

Then as $Q_{\mathrm{H}}$ decreases, $\pi_{1 \mathrm{H}}^{*}$ decreases and $\pi_{2 \mathrm{H}}^{*}$ increases; $\pi_{1 \mathrm{H}}^{*}=0.0218221 \Theta^{4}$ and $\pi_{2 \mathrm{H}}^{*}=0.0026475 \Theta^{4}$ for $Q_{\mathrm{H}}=0.460496 \Theta$ and, $\pi_{1 \mathrm{H}}^{*}=0.0213134 \Theta^{4}$ and $\pi_{2 \mathrm{H}}^{*}=$ $0.002843 \Theta^{4}$ for $Q_{\mathrm{H}}=0.4508 \Theta$. Finally, total domestic welfare is the sum of consumer surplus, $C S_{\mathrm{H}}$, and $\pi_{2 \mathrm{H}}^{*}$, where

$$
\begin{aligned}
C S_{\mathrm{H}}= & 0.5 s_{1 \mathrm{H}}^{*}\left[\Theta^{2}-\left(\Theta-x_{1 \mathrm{H}}^{*}\right)^{2}\right]+0.5 s_{2 \mathrm{H}}^{*}\left[\left(\Theta-x_{1 \mathrm{H}}^{*}\right)^{2}-\left(\Theta-x_{1 \mathrm{H}}^{*}-x_{2 \mathrm{H}}^{*}\right)^{2}\right] \\
& -p_{1 \mathrm{H}}^{*} x_{1 \mathrm{H}}^{*}-p_{2 \mathrm{H}}^{*} x_{2 \mathrm{H}}^{*} \\
= & \left(\Theta-Q_{\mathrm{H}}\right)\left(\Theta^{3}+\Theta^{2} Q_{\mathrm{H}}-5 \Theta Q_{\mathrm{H}}^{2}+19 Q_{\mathrm{H}}^{3}\right) / 32 \\
T W_{\mathrm{H}}= & \left(\Theta-Q_{\mathrm{H}}\right)\left(\Theta^{3}-\Theta^{2} Q_{\mathrm{H}}-\Theta Q_{\mathrm{H}}^{2}+9 Q_{\mathrm{H}}^{3}\right) / 16
\end{aligned}
$$

Note that $\mathrm{d} C S_{\mathrm{H}} / \mathrm{d} Q_{\mathrm{H}}>0$, while $T W_{\mathrm{H}}$ increases with $Q_{\mathrm{H}}$ for $Q_{\mathrm{H}}>0.3745 \Theta$, and decreases otherwise; further, its maximum value is at $Q_{\mathrm{H}}=0.460496 \Theta$ and is equal to $0.0406755 \Theta^{4}$ (for $Q_{\mathrm{H}}=0.4508 \Theta, T W_{\mathrm{H}}=0.041769 \Theta^{4}$ ).

(ii) Foreign firm low quality (Case $L$ ): Let $Q_{\mathrm{L}} \leqslant 0.274696 \Theta$ be imposed on the low-quality foreign firm. Then the foreign firm chooses $x_{2 \mathrm{~L}}=\min \left[Q_{\mathrm{L}}, 0.5(\Theta-\right.$ $\left.x_{1}\right)$ ]. We assume first that the quota is binding and then we find the maximum $Q_{\mathrm{L}}$ such that this is true in equilibrium. Hence, $x_{2 \mathrm{~L}}^{*}=Q_{\mathrm{L}}, x_{1 \mathrm{~L}}^{*}=0.5\left[\Theta-\left(s_{2} Q_{\mathrm{L}} / s_{1}\right)\right]$, and from Eq. (3) we get, $p_{1 \mathrm{~L}}^{*}=0.5\left(\Theta s_{1}-Q_{\mathrm{L}} s_{2}\right)$ and $p_{2 \mathrm{~L}}^{*}=0.5\left(s_{2} / s_{1}\right)\left(\Theta s_{1}-\right.$ $\left.2 s_{1} Q_{\mathrm{L}}+s_{2} Q_{\mathrm{L}}\right)$. Then the net profits are, $\pi_{1 \mathrm{~L}}=\left(1 / 4 s_{1}\right)\left(\Theta s_{1}-Q_{\mathrm{L}} s_{2}\right)^{2}-\left(s_{1}^{2} / 2\right)$ and $\pi_{2 \mathrm{~L}}=0.5\left(s_{2} Q_{\mathrm{L}} / s_{1}\right)\left[\Theta s_{1}-2 s_{1} Q_{\mathrm{L}}+s_{2} Q_{\mathrm{L}}\right]-\left(s_{2}^{2} / 2\right)$. Defining $k=(1 / \lambda)=s_{2} / s_{1}<1$, we can write the focs as, 


$$
\begin{aligned}
& s_{2}=0.5 \Theta Q_{\mathrm{L}}-Q_{\mathrm{L}}^{2}+k Q_{\mathrm{L}}^{2} \\
& s_{1}=0.25\left(\Theta^{2}-Q_{\mathrm{L}}^{2} k^{2}\right)
\end{aligned}
$$

Dividing Eq. (A7) and Eq. (A8) and rearranging we get,

$$
\left(k^{3}+4 k-4\right) Q_{\mathrm{L}}^{2}+2 \Theta Q_{\mathrm{L}}-k \Theta^{2}=0
$$

Solving Eq. (A9) for $Q_{\mathrm{L}}$ we get,

$$
Q_{\mathrm{L}}=\Theta\left[-1+\sqrt{ }\left(1-4 k+4 k^{2}+k^{4}\right)\right] /\left(k^{3}+4 k-4\right) \equiv \varphi(k)
$$

Note from Eq. (A7) that if $Q_{\mathrm{L}}=0$, then $s_{2}=0$, thus $k=0$, i.e. $\varphi(0)=0$; also, that $\varphi^{\prime}(k)>0$ in the relevant range (see below). Substituting Eq. (A10) into Eq. (A7) and Eq. (A8) we get $s_{2 \mathrm{~L}}^{*}, s_{1 \mathrm{~L}}^{*}$ and $s_{\mathrm{AVL}}$ as functions of $k$.

It can now be checked that $Q_{\mathrm{L}} \leqslant 0.5\left(\Theta-x_{1 \mathrm{~L}}^{*}\right.$ ) for all $k \leqslant 0.3596118$ (or equivalently, for all $\left.Q_{\mathrm{L}} \leqslant 0.274696 \Theta\right)$. Plotting $s_{2 \mathrm{~L}}^{*}, s_{1 \mathrm{~L}}^{*}$ and $s_{\mathrm{AVL}}$ in the relevant range, i.e. $0 \leqslant k \leqslant 0.3596118$, we observe that $\mathrm{d} s_{1 \mathrm{~L}}^{*} / \mathrm{d} Q_{\mathrm{L}}<0, \mathrm{~d} s_{2 \mathrm{~L}}^{*} / \mathrm{d} Q_{\mathrm{L}}>0$ and $\mathrm{d} s_{\mathrm{AVL}} / \mathrm{d} Q_{\mathrm{L}}<0$ (note that, $s_{1 \mathrm{~L}}^{*}=0.25 \Theta^{2}$ for $Q_{\mathrm{L}}=0$ ). Further, substituting $s_{2 \mathrm{~L}}^{*}, s_{1 \mathrm{~L}}^{*}$ and $Q_{\mathrm{L}}$ into the expressions of profits, we get the equilibrium profits, $\pi_{i \mathrm{~L}}^{*}, i=1,2$ as functions of $k$. Again, by plotting the profits in the relevant range, we observe that $\mathrm{d} \pi_{1 \mathrm{~L}}^{*} / \mathrm{d} Q_{\mathrm{L}}<0$ and $\mathrm{d} \pi_{2 \mathrm{~L}}^{*} / \mathrm{d} Q_{\mathrm{L}}>0$. Also, $\left(\pi_{1 \mathrm{~L}}^{*}, \pi_{2 \mathrm{~L}}^{*}\right)=\left(0.0196 \Theta^{4}, 0.00275 \Theta^{4}\right)$ for a quota at the free trade level. Finally, total domestic welfare is the sum of $C S_{\mathrm{L}}$ and $\pi_{1 \mathrm{~L}}^{*}$. Using a similar expression as in Eq. (A5) and substituting equilibrium qualities, quantities and prices, we get $C S_{\mathrm{L}}$ and $T W_{\mathrm{L}}$ as functions of $k$. Finally by plotting then in the relevant range, we observe that $\mathrm{d} C S_{\mathrm{L}} / \mathrm{d} Q_{\mathrm{L}}>0$, while $\mathrm{d} T W_{\mathrm{L}} /$ $\mathrm{d} Q_{\mathrm{L}}<0$. Also, $T W_{\mathrm{L}}=0.0625 \Theta^{4}$ for $Q_{\mathrm{L}}=0$ and $T W_{\mathrm{L}}=0.059136 \Theta^{4}$ for a quota at the free trade level. Q.E.D.

\section{Appendix B}

Proof of Proposition 3. First, BRs are downwards slopping, since from Eqs. (7) and (8) for $i=1,2$, we get (with $\pi_{x 1 x 2}^{i} \equiv \partial^{2} \pi^{i} / \partial x_{1} \partial x_{2}$, etc.)

$$
\begin{aligned}
\pi_{x 1 x 2}^{i} & =u\left(s_{2}\right) \theta_{x i}\left(x_{i}+x_{2}\right)\left[1+\theta_{x 1 x 2}\left(x_{1}+x_{2}\right) x_{i} / \theta_{x i}\left(x_{1}+x_{2}\right)\right] \\
& =-\left[u\left(s_{2}\right) / f\left(\theta\left(x_{1}+x_{2}\right)\right)\right]\left[1+f_{\theta}\left(\theta\left(x_{1}+x_{2}\right)\right) x_{i} / f^{2}\left(\theta\left(x_{1}+x_{2}\right)\right)\right]<0
\end{aligned}
$$

The last inequality is due to our assumption of increasing hazard rate, which implies that for all $\theta, 1+[1-F(\theta)] f_{\theta}(\theta) / f^{2}(\theta)>0$, and also to the fact that $x_{i}<1-F\left(\theta\left(x_{1}+x_{2}\right)\right)$. Further, using similar arguments we obtain,

$$
\begin{aligned}
\pi_{x 2 x 2}^{2}= & -\left[u\left(s_{2}\right) / f\left(\theta\left(x_{1}+x_{2}\right)\right)\right]\left[2+f_{\theta}\left(\theta\left(x_{1}+x_{2}\right)\right) x_{2} / f^{2}\left(\theta\left(x_{1}+x_{2}\right)\right)\right] \\
& -m\left[\partial M C^{2}\left(m x_{2}, s_{2}\right) / \partial x_{2}\right]<0
\end{aligned}
$$




$$
\begin{aligned}
\pi_{x 1 x 1}^{1}= & -\left[\left\{u\left(s_{1}\right)-u\left(s_{2}\right)\right\} / f\left(\theta\left(x_{1}\right)\right)\right]\left[2+f_{\theta}\left(\theta\left(x_{1}\right)\right) x_{1} / f^{2}\left(\theta\left(x_{1}\right)\right)\right] \\
& -\left[u\left(s_{2}\right) / f\left(\theta\left(x_{1}+x_{2}\right)\right)\right]\left[2+f_{\theta}\left(\theta\left(x_{1}+x_{2}\right)\right) x_{1} / f^{2}\left(\theta\left(x_{1}+x_{2}\right)\right)\right] \\
& -m\left[\partial M C^{1}\left(m x_{1}, s_{1}\right) / \partial x_{1}\right]<0
\end{aligned}
$$

That is, the second-order conditions are satisfied. It is now easy to check that $\left|\pi_{x i x i}{ }^{i}\right|>\left|\pi_{x i x j}{ }^{i}\right|$, i.e. the slope of the BRs is less than 1 in absolute value and thus the sufficient conditions for uniqueness of the equilibrium hold. Note also that, $D \equiv \pi_{x 1 \times 1}^{1} \pi_{x 2 x 2}^{2}-\pi_{x 1 x 2}^{1} \pi_{x 2 x 1}^{2}>0$.

We now turn to the comparative statics. To see how the equilibrium quantities respond to an increase in $s_{i}, i=1,2$, we totally differentiate Eqs. (7) and (8). Then

$$
\begin{aligned}
& \partial x_{2}^{*} / \partial s_{1}=\pi_{x 1 s 1}^{1} \pi_{x 1 x 2}^{2} / D ; \partial x_{1}^{*} / \partial s_{1}=-\pi_{x 2 x 2}^{2} \pi_{x 1 s 1}^{1} / D \\
& \partial x_{1}^{*} / \partial s_{2}=\left[-\pi_{x 1 s 2}^{1} \pi_{x 2 x 2}^{2}+\pi_{x 2 s 2}^{2} \pi_{x 1 x 2}^{1}\right] / D ; \\
& \partial x_{2}^{*} / \partial s_{2}=\left[-\pi_{x 1 x 1}^{1} \pi_{x 2 s 2}^{2}+\pi_{x 2 x 1}^{2} \pi_{x 1 x 2}^{2}\right] / D
\end{aligned}
$$

where

$$
\begin{aligned}
& \pi_{x 1 s 2}=-u\left(s_{2}\right)\left[\theta\left(x_{1}^{*}\right)-\theta\left(x_{1}^{*}+x_{2}^{*}\right)+\theta_{x 1}\left(x_{1}^{*}\right) x_{1}^{*}-\theta_{x 1}\left(x_{1}^{*}+x_{2}^{*}\right) x_{1}^{*}\right] \\
& \pi_{x 1 s 1}^{1}=\left[\theta\left(x_{1}^{*}\right)+\theta_{x 1}\left(x_{1}^{*}\right) x_{1}^{*}\right] u^{\prime}\left(s_{1}\right)-\partial M C^{1}\left(m x_{1}^{*}, s_{1}\right) / \partial s_{1} \\
& \pi_{x 2 s 2}^{2}=\left[\theta\left(x_{1}^{*}+x_{2}^{*}\right)+\theta_{x 2}\left(x_{1}^{*}+x_{2}^{*}\right) x_{2}^{*}\right] u^{\prime}\left(s_{2}\right)-\partial M C^{2}\left(m x_{2}^{*}, s_{2}\right) / \partial s_{2}
\end{aligned}
$$

From Eq. (7), $\left[\theta\left(x_{1}^{*}+x_{2}^{*}\right)+\theta x_{2}\left(x_{1}^{*}+x_{2}^{*}\right) x_{2}^{*}\right]>0$, and given our assumption that $\partial M C^{i} / \partial s_{i}$ is small enough, we get $\pi_{x 2 s 2}^{2}>0$ and thus $B R_{2}$ shifts out with $s_{2}$. for the problem not to be trivial, the marginal revenue of a monopolist must be positive, which implies that $\left[\theta\left(x_{1}^{*}\right)+\theta_{x 1}\left(x_{1}^{*}\right) x_{1}^{*}\right]>0 .^{22}$ As $\partial M C^{i} / \partial s_{i}$ is small enough, we obtain $\pi_{x 1 x 2}^{1}>0$ and thus $B R_{1}$ shifts out with $s_{1}$. Finally, [ $\theta\left(x_{1}^{*}\right)-$ $\left.\theta\left(x_{1}^{*}+x_{2}^{*}\right)+\theta_{x 1}\left(x_{1}^{*}\right) x_{1}^{*}-\Theta_{x 1}\left(x_{1}^{*}+x_{2}^{*}\right) . x_{1}^{*}\right]$ must be positive, since it is proportional to the reduction in the high-quality firm's revenues due to its competition with the low-quality firm. Hence, $\pi_{x 1 s 2}^{1}<0$, and thus $B R_{1}$ shifts in with $s_{2}$. Finally, it can be checked that $\partial x_{2}^{*} / \partial s_{1}<0, \partial x_{1}^{*} / \partial s_{1}<0, \partial x_{1}^{*} / \partial s_{2}<0$ and $\partial_{x 2}^{*} / \partial s_{2}>0$. Q.E.D.

\section{References}

Aw, Bee Yan, Roberts, Mark J., 1986. Measuring quality change in quota-constrained import markets:

The case of US footwear, J Intl Economics 21, 45-60.

\footnotetext{
${ }^{22}$ One can also think that $\left[\theta\left(x_{1}\right)+\theta_{x 1}\left(x_{1}\right) x_{1}\right]$ is proportional to the marginal revenue on the total demand, while $\left[\theta\left(x_{1}+x_{2}\right)+\theta_{x 2}\left(x_{1}+x_{2}\right) x_{2}\right]$ on the residual demand. As the latter is positive in equilibrium, it is reasonable that the former is also positive.
} 
Boorstein, R., Feenstra, R.C., 1991. Quality upgrading and its welfare cost in US steel imports. In: Helpman, E., Razin, A. (Eds.), International Trade and Trade Policy, MIT Press, pp. 167-186.

Das, S.P., Donnenfeld, S., 1987. Trade policy and its impact on the quality of imports: A welfare analysis. Journal of International Economics 23, 77-95.

Das, S.P., Donnenfeld, S., 1989. Oligopolistic competition and international trade: Quantity and quality restrictions. Journal of International Economics 27, 299-318.

Falvey, R., 1979. The composition of trade within import restricted categories. Journal of Political Economy 87 (5), 1105-1114.

Feenstra, R.C., 1988. Quality change under trade restrictions: Theory and evidence. Quarterly Journal of Economics 102, 131-146.

Gabszewicz, J.J., Thisse, J.F., 1980. Entry (and exit) in a differentiated industry. Journal of Economic Theory 22, 327-338.

Gabszewicz, J.J., Thisse, J.F., 1986. On the nature of competition with differentiated products. The Economic Journal 96 (31), 160-172.

Harris, R., 1985. Why voluntary export restraints are voluntary?. Canadian Journal of Economics 8, 799-809.

Herguera, I., Kujal, P., Petrakis, E., 1994. Quantity restrictions and endogenous quality choice, Working Paper 94-39, Universidad Carlos III.

Herguera, I., Kujal, P., Petrakis, E., 1996. Endogenous quality and leapfrogging-provoking trade policies, Mimeo, Universidad Carlos III.

Herguera, I., Kujal, P., Petrakis, E., 1997. Non-credible policies and leapfrogging in vertically differentiated industries, Working Paper 97-73, Universidad Carlos III.

Krishna, K., 1989. Trade restrictions as facilitating practices. Journal of International Economics 26, 251-270.

Krishna, K., 1987. Tariffs vs. quotas with endogenous quality. Journal of International Economics 23, 97-122.

Krishna, K., 1990. Export restrictions with imperfect competition: A selective survey, NBER Working Paper No. 3244, January.

Lutz, S., 1997. Quotas with vertical differentiation and price competition, Mimeo, University of Bonn.

Motta, M., 1993. Endogenous quality choice: price vs. quantity competition. The Journal of Industrial Economics 2, 113-132.

Reitzes, J.D., 1991. The impact of quotas and tariffs on strategic R\&D behavior. International Economic Review 32 (4), 985-1007.

Ries, J.C., 1993. Voluntary export restraints, profits, and quality adjustment, Canadian Journal of Economics 3, 688-706.

Santoni, G.J., Van Cott, T.N., 1980. Import quotas: The quality adjustment problem. Southern Economic Journal 46 (4), 1206-1211.

Shaked, A., Sutton, J., 1982. Relaxing price competition through product differentiation. Review of Economic Studies 49, 3-13.

Shaked, A., Sutton, J., 1983. Natural oligopolies. Econometrica 51 (5), 1469-1483.

Shaked, A., Sutton, J., 1984. Natural oligopolies and international trade. In: Kierzkowski, H. (Ed.), Monopolistic Competition and International Trade, Oxford University Press, pp. 34-50.

Sutton, J., 1992. Sunk Costs and Market Structure, MIT Press, pp. 70-71.

Tirole, J., 1989. The Theory of Industrial Organization, The MIT Press, p. 156. 